\title{
Erratum
}

\section{REML estimates of genetic parameters of sexual dimorphism for wing and thorax length in Drosophila melanogaster}

Sandrine Mignon-Grasteau, Jean David, Patricia Gibert, Hélène Legout, Georges Pétavy, Brigitte Moreteau and Catherine Beaumont

\section{J. Genet. 83, 163-170}

The printed article (August 2004 issue) has a wrong figure 5. The correct figure 5 is printed below. A corrected PDF file is available on the website (http://www.ias.ac.in/jgenet).

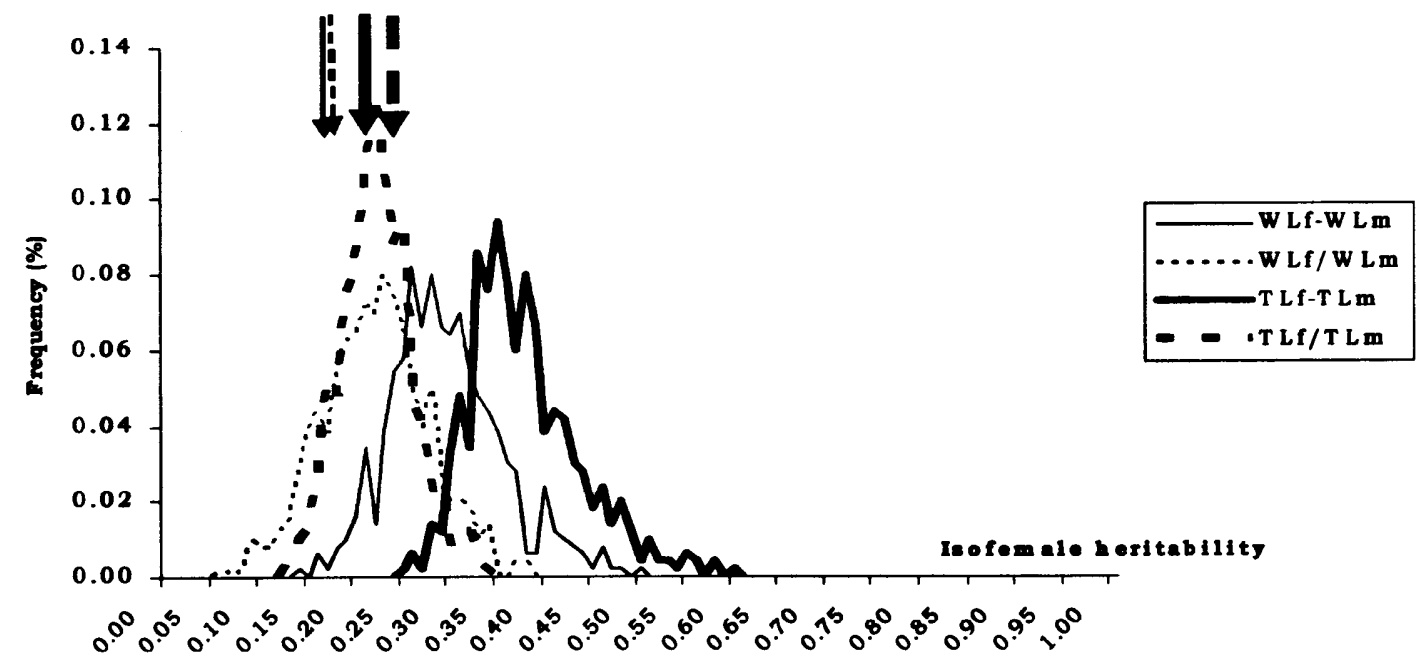

